\title{
AREVA Fatigue Concept - A Three Stage Approach to the Fatigue Assessment of Power Plant Components
}

\author{
Jürgen Rudolph*, Steffen Bergholz, Benedikt Heinz and Benoit Jouan \\ AREVA NP GmbH \\ Erlangen \\ Germany
}

\section{Introduction}

\subsection{General remarks}

Within the continuously accompanying licensing process for NPPs until the end of their operational lifetime, the ageing and lifetime management plays a key role. Here, one of the main tasks is to assure structural integrity of the systems and components. With the help of the AREVA Fatigue Concept (AFC), a powerful method is available. The AFC provides different code-conforming fatigue analyses (e.g. according to the wide spread ASME code [1]) based on realistic loads. In light of the tightening fatigue codes and standards, the urge is clearly present that, in order to still be able to comply with these new boundaries, margins which are still embedded within most of the fatigue analyses in use, have to be reduced. Moreover, thermal conditions and chemical composition of the fluid inside the piping system influences the allowable fatigue levels, which have come under extensive review due to the consideration of environmentally assisted fatigue (EAF) as proposed in the report [2]. Therefore, for highly loaded components, some new and improved stress and fatigue evaluation methods, not overly conservative, are needed to meet the increasingly stringent allowable fatigue levels. In this context, the fatigue monitoring system FAMOS, central module of AFC, is able to monitor and record the real local operating loads. The different modules of the AFC are schematically represented in Figure 1.

\subsection{Safety concept context of NPPs}

NPPs are subject of particular safety requirements due to the increased risk potential. The utmost aim from the point of view of safety in the design as well as the plant operation is the prevention of unforeseen events or accidents.

Ageing effects may also induce unexpected events during operation. A comprehensive ageing management is required in order to avoid these a priori. Particularly regarding the aspects of new lifetime periods of nuclear power generation works (60 years of operation for

${ }^{*}$ Corresponding Author 
new NPPs such as AREVA's EPR ${ }^{\mathrm{TM}}$ ) or due to lifetime extension projects (e.g. in the USA, Sweden or Switzerland) there is an increasing need of knowing the current state of the plant exactly in order to enable a qualified respective assessment. Of course, the knowledge of the occurred and expected loading of the power plant components is an essential prerequisite for such an assessment. The operation of a new NPP will extend to three generations of operational staff. Conceptual long term solutions are required in this context. I.e., all relevant load data should be recorded in a way that future staff still have access to these data and can consider them in the evaluation of the plants.

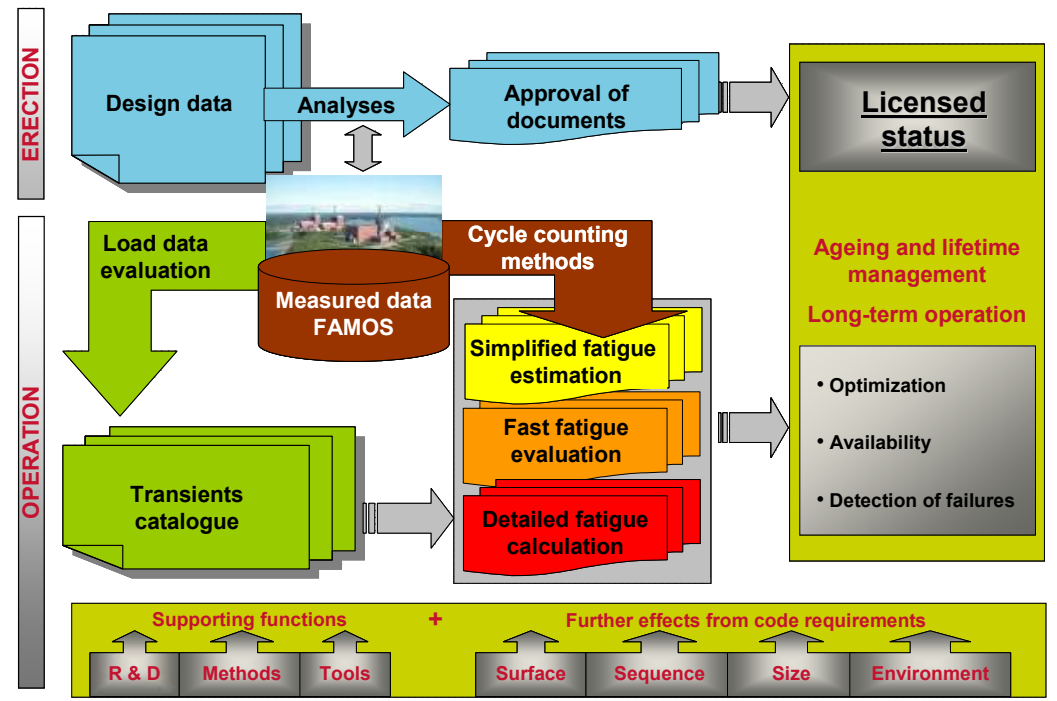

Fig. 1. Modules of the AFC

\subsection{Fatigue}

The fatigue check takes a central position within the ageing management. The successful fatigue check shows the design-conforming state of cyclic operational loads. During operation of NPPs, particularly the thermal cyclic loadings are fatigue relevant. They are due to transient states of operation. E.g., respective cold or hot feed conditions occur during start-up and shutdown as well as testing conditions of the safety equipment. Furthermore, permanently occurring mixing events of hot and cold flows at junction locations (t-sections) may induce high cycle fatigue loads. Certain plant conditions may induce temperature stratification events within larger pipes at lower flow rates and an existing temperature difference. These phenomena may equally induce cyclic loads in the pipeline and the attached components. Of course, cyclic mechanical loads such as internal pressure or piping loads have to be considered for the fatigue check as well. Until now, the design and operation of NPPs was concentrated on the purpose of base load generation for the respective electrical network. In the future, NPPs will have to take increasing parts of the average and peak load generation due to the growing utilization of renewable energy sources such as wind and solar energy. This generates permanently changing states of the plant which have to be considered within the fatigue check. All these expected loads are examined in the design phase of a power plant as well as 
recorded and described in a design transient catalogue. These so called design transients are characterized by the expected temperature ranges, temperature change rates and the expected frequencies of occurrence. Furthermore, the expected internal pressure and - if applicable stratification states are considered. This transient catalogue constitutes the basis of the design fatigue checks. This first fatigue check is part of the licensing documents and should also indicate fatigue relevant positions and plant processes. If necessary, modifications of the plant processes and/or components are carried out in the design phase with the aim of eliminating potentially critical positions. The task of the fatigue check changes somewhat during the operation of the NPP. In this phase, the fatigue check is primarily used to show that the operation of the plant is within the specified limits. That is to say, the fatigue usage factor for the relevant components has to be reported in a regulated cyclic sequence. As the operational processes differ even for identical technological procedures a simple counting of technological procedures (events) will not necessarily deliver a covering fatigue usage factor. It is also possible to overestimate fatigue usage in case of conservatively specified design transients.

\subsection{Local monitoring concept}

The complex fluid flow events occurring during the operation of NPPs are influenced by the automatic operational control processes. Nevertheless, as a consequence of the manifold manual intervention opportunities equal technological processes may induce different local loading sequences for the components. In other words, an assessment of components exclusively based on operational measuring instrumentation is insufficient. Local data acquisition and monitoring of local loads at the fatigue relevant components is the better solution. Local effects such as the swapping flow after feeding interruption can only be recorded in the load data set this way. It is to be pointed out that the safety check against cyclic loads of the components has to be a permanent operation accompanying procedure. The German KTA rules regulate this issue as part of the rule for operational monitoring (KTA 3201.4) [3].

\subsection{Modified codes}

On one hand, the checks have to be harmonized with the valid design code. On the other hand, the state of the art in science and technology has to be considered. Recently, the detrimental influence of the medium (high temperature reactor water) on the fatigue process - which has been examined since the 1980ies - is the subject of code modifications tending towards tightening code rules. The term environmentally assisted fatigue (EAF) is synonymous to the corrosive influence of the medium on the fatigue behavior. The usual way of considering EAF in fatigue analysis is the application of penalty factors $\mathrm{F}_{\mathrm{en}}$. The modified code rules mostly based on [2] have to be considered and applied both within the lifetime extension projects and the new built projects of NPPs.

\subsection{Fatigue monitoring systems}

During the early operation of NPPs in the 1970ies and 1980ies local loads occurred at different locations causing fatigue cracks. These were either due to new loading conditions which were not considered in the design phase (e.g. temperature stratification) or insufficient manufacturing quality (e.g. welded joints). These problems constituted the 
starting signal for the development of fatigue monitoring systems. Thus, FAMOS was for instance developed by then Siemens KWU at the end of the 1980ies and installed in German NPPs. At that time, this was a very progressive data logging system. Henceforth, it was possible to measure the local loading effects. The fatigue relevance of those effects was analyzed by simple assessment methods. These experiences gave rise to a better understanding of the ongoing loading phenomena. The fatigue assessment induced the necessity of retrofitting of components or the modification of the operating mode. For instance, the feedwater sparger of the steam generator was subsequently designed in a way that the stresses of cyclically occurring stratification transients were minimized. Nevertheless, the technology of the data logging system at that time still had certain limits with respect of the frequency of data logging and the recording and storage. A data logging frequency of $10 \mathrm{~s}(0.1 \mathrm{~Hz})$ constituted the upper limit (nowadays, $1 \mathrm{~s}$ respectively $1 \mathrm{~Hz}$ is usual). Furthermore, the capacitive effect of the applied measurement sections was underestimated in their transient behavior. Nowadays, this effect is appropriately considered by correction factors specific to the respective measurement section.

\subsection{New software, hardware and ageing requirements}

Hence, these limits do not exist anymore in the application of up-to-date data logging systems. The application of modern BUS technologies paves the way for an economic and flexible measuring system without long cables. Handling and performance has been significantly improved for the modern systems. AREVA offers FAMOSi as a modern data logging system of that kind. It delivers the data base for the further fatigue monitoring and for the further assessment in a highly reliably way.

\subsection{Data post processing and evaluation of cumulative usage factors (CUFs)}

As it was mentioned before the evaluation of the recorded measurement data is done by application of a three staged assessment system. Only those analyses are applied that are required for the fatigue assessment of the according component. If the CUF obtained by application of the first analysis stage - the simplified fatigue estimation (SFE) - falls below the defined target value no further evaluation will be required. If it does not the second stage - fast fatigue evaluation (FFE) - will be activated and so on.

All data have to undergo a plausibility check before being further processed. The plausibility check enables a data control based on predefined limiting values. Erroneous data blocks originating for instance from electromagnetic pulses (e.g. switching operations within the main coolant pump) are detected by identification of physically questionable values of the temperatures or their gradients. These data sets are corrected to logical values. The correction is precisely recorded and can be reproduced at any time. Thus, the generated plausible data set constitutes the basis for the further data processing and assessment.

\section{Design analysis before operation}

Before commissioning and operation of the plant, a catalogue of thermal transients is compiled. These thermal transients are considered as design transients in contrast with the real transients based on temperature measured during operation. In the past, the 
anticipated transients were covering 40 years of plant operation. Now, the period to be covered is 60 years. Moreover, the specification is done for normal, upset, emergency and testing conditions. The design thermal transients are specified according to different plant models and experiences. They should always be conservative concerning frequency of occurrences, temperature range, rate of temperature change and load type (thermal stratification, thermal shock). Due to this conservatism, the usage factor calculated in the design phase, under normal circumstances, will be more severe than the results of the detailed fatigue calculation performed at a later operation stage taking into account the real operational thermal loads. As a consequence, usage factors around 1.0 are still tolerable in the design phase. They indicate the fatigue sensitive positions. These locations are selected for future instrumentation and non-destructive testing. Design improvements of components, depending on the calculated fatigue usage factors, can also be taken into account at this early stage. Additionally, optimization of operating modes can be considered. Thermal transients with low influence on fatigue behavior are identified as well. Depending on the different design codes [1], [4], [5], some procedures can allow the exemption of non significant loads. In the end, the predicted fatigue usage factors, which were calculated with design transients, shall be verified and the fatigue status shall be updated during lifetime operation.

\section{Fatigue monitoring system}

The acquisition of realistic operational load data in the power plant is one essential pillar of the AFC. Its function is to determine the realistic thermal loads. FAMOS was developed in the early eighties. At that time, German licensing authorities demanded for the realization of a comprehensive measurement program in one German NPP. This was in order to get detailed information on the real component loadings during plant operation. This proof should give the information that the real operating conditions are not different from the design data. At that occasion, the advantages of monitoring real operating loads and using the measured data as an input for fatigue analyses became obvious. Therefore, a sophisticated fatigue monitoring system was developed. As a consequence, many NPPs in Germany and abroad were equipped with FAMOS (see also [6]).

Depending on each power plant, a fatigue handbook is developed to identify the locations relevant to fatigue in the NPP. The instrumentation of these locations is specific for each plant and depends on system design and further requirements.

For the acquisition of load data FAMOS uses two different methods: the global fatigue monitoring and the local fatigue monitoring [7]. The global monitoring is made by existing operational measurement. The corresponding operational signals could be fluid pressure, fluid temperature, the position of valves etc. measured at different parts of the systems.

Local fatigue monitoring is located at fatigue relevant locations at the outer surface of pipes and is based on additional temperature measurement by means of thermocouples. The thermocouples are manufactured as measurement sections.

Figure 2 shows the typical locations of measurement sections in a pressurized water reactor (PWR). Indeed, FAMOS gathers measurement sections, which are mostly located on the: 
- $\quad$ primary loops

- surge line

- $\quad$ spray lines

- volume control system

- feedwater system and further positions.

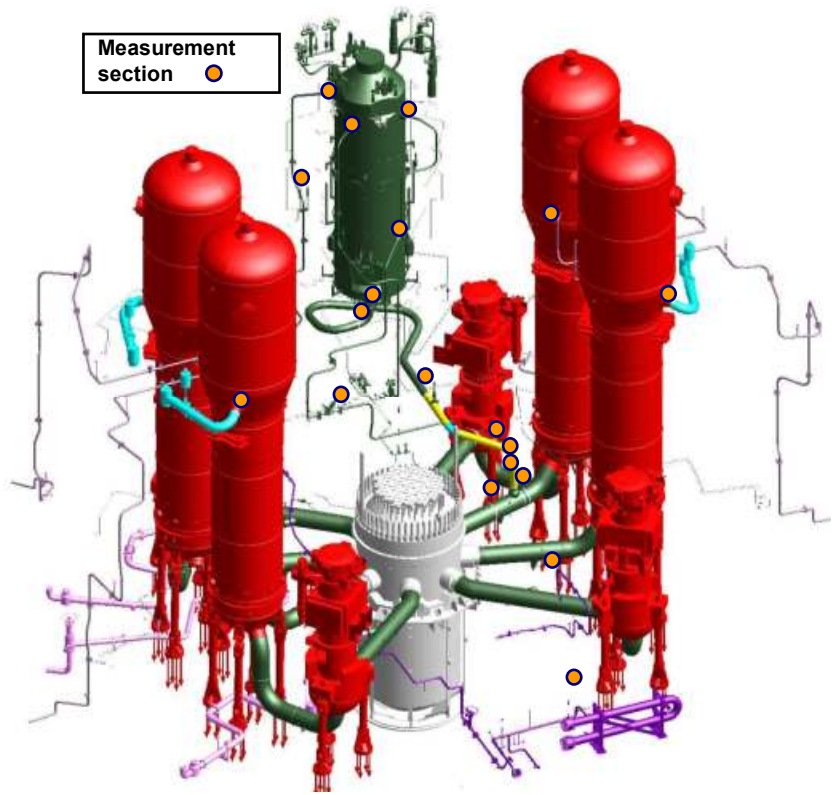

Fig. 2. FAMOS measurement sections in a PWR

The different FAMOS measurement sections can be composed of seven or more thermocouples if some thermal events like stratification are suspected (horizontally installed pipes). However, in case of plug flow the application of only two thermocouples is sufficient (vertically installed pipes).

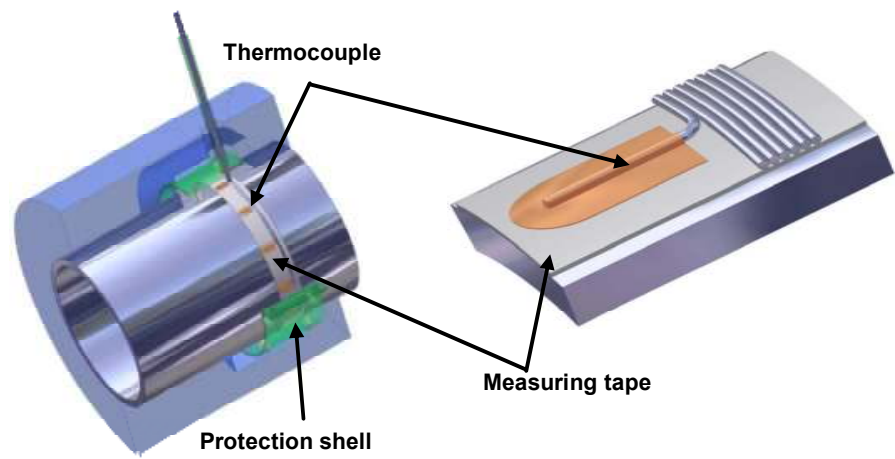

Fig. 3. FAMOS principle 
Figure 3 shows how the application of thermocouples at the outer surface of a pipe is performed. More details on the technical bases of FAMOS can be found in [8].

Each measurement section consists of the thermocouples installed on a thin metal tape and a robust protection shell to prevent the thermocouples from being damaged. Both, metal tape and protection shell are installed around the pipe under the piping insulation. The installation takes place at a certain distance to pipe welds. Thus, the dismounting of measurement sections during an ultrasonic testing of the weld is unnecessary. Furthermore, a distance to thick walled components (e.g. nozzles) is needed in order to minimize the thermal impact on the temperature measurement.

The measurement sections are designed for a fast mounting process. A very short installation time is absolutely necessary to ensure low dose rates for the mounting staff. Special manufacturing processes and thermal responses tests of the thermocouples guarantee realistic thermal load data. Actual measurement sections are characterized by a minimization of heat capacity effects and excellent thermal sensitivity.

All thermocouples are wired with extension lines to junction boxes where the cold junction compensation of the thermo voltage signal is performed. For the compensation a board with an isothermal terminal for up to 30 channels is used to connect the wires made of thermocouple material with a trunk cable made of copper. The temperature at the isothermal terminal is measured with a resistance thermometer. The voltage signals from different junction boxes are connected to the information and control system (I\&C) of FAMOS. That system consists of two or more information modules with signal processing units and analogto-digital converters. The information modules are connected by means of a data bus to a processing unit. The data of all thermocouples are analyzed, stored and transferred to a computer network in real time. To avoid a high data volume in the storage system a data reduction method is used for the samples of the signals. By application of the bandwidth method samples will only be stored if signals leave the bandwidth. Thus, it is ensured that all samples of fatigue relevant load data during transients are stored and only a few samples during steady state operating mode of the plant with no fatigue relevant transients.

The information modules and the processing unit are installed within the containment of the power plant. All requirements of the containment environment such as temperature, humidity, atmosphere and material restrictions have been considered during engineering and design of the I\&C components. The system is equipped with redundant power supply and a diagnostic system to detect malfunctions in different modules. Thus, a long term monitoring and storage of load data in a containment environment is ensured.

Outside the containment a sever unit is installed in the safeguards building, main control side room or other computer rooms of the power plant. That server stores all load data in a database over years. In addition to the FAMOS data, load data of the global instrumentation are also stored in the sever unit. For the connection of the server unit with the processing unit inside the containment fibre optic cables or normal ethernet connections made of copper are used. These cables run in special penetrations through the pressure-sealed and gas tight containment wall.

By means of a network connection to the server unit all data of FAMOS and the global monitoring can be viewed in real time on any connected computer. The access to the database 
features the view on the load data of several years of power plant operation. The real time data analyzing process done by the processing unit generates messages about high thermal loads or malfunctions automatically. Thresholds for temperature rate of change or thermal stratification can be set. Is the threshold reached during a transient the system generates a warning about high thermal loads. In combination with valve position signals from the global monitoring, the system detects insufficiently closed valves even if the valve position indicates it.

With the help of automated warnings, unfavourable thermal load events can be analyzed and operating modes optimized. For the purpose of preventive maintenance FAMOS offers all necessary information to prevent the plant's components from avoidable load events.

The FAMOS I\&C system operates in real time with signals of 120 or more than 300 thermocouple channels. The number of channels depends on the power plant layout, the number of primary loops and the monitored components. The engineering of FAMOS in a NPP starts with the generation of a FAMOS manual. This process contains a deep analysis to identify components relevant to fatigue in the primary, secondary, auxiliary and safeguards systems. To do so, design documents, operating experience and feedback from similar plants are considered. A measurement point plan is elaborated and all activities are coordinated with the plant operator and, if required, with independent experts.

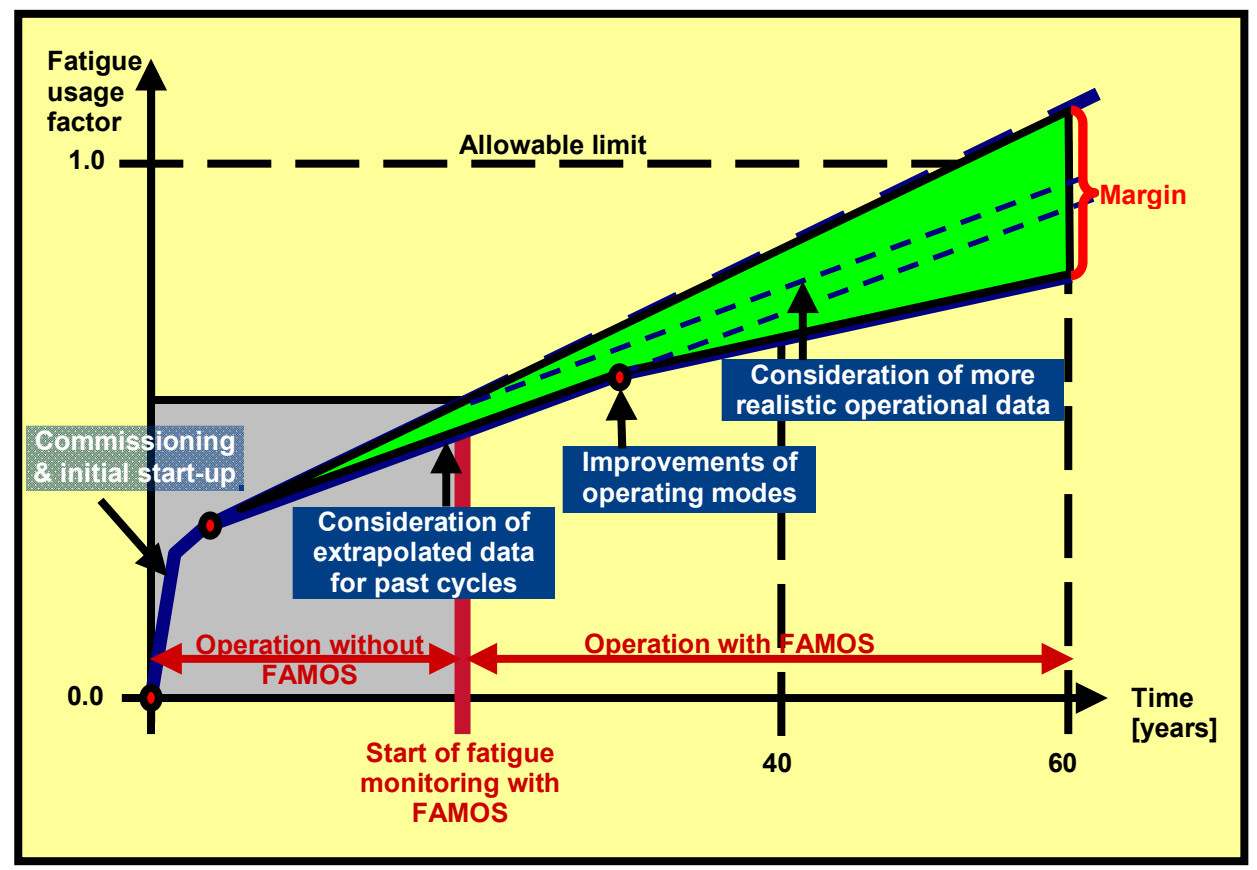

Fig. 4. Development of fatigue usage factor considering local monitoring and improvements

If FAMOS is installed before commissioning of the plant the fatigue status can be calculated over the complete lifetime with realistic load data. Indeed, the commissioning phase is often characterized by the highest loads of the entire lifetime of the power plant. But an installation into a running plant is useful after several years of operation e.g. during lifetime extension. 
Getting the real measurements at this stage implies a consequent reduction of the fatigue usage factor when the later detailed fatigue calculation is required as explained in Figure 4.

The objectives of FAMOS are summarized here below:

- to determine the fatigue status of the most highly stressed components

- $\quad$ to identify and optimize the operating modes which are unfavourable to fatigue e.g. valve leakages

- to improve the catalogue of transients used at the design phase

- $\quad$ to establish a basis for fatigue analysis based on realistic operating loads

- to use the results for lifetime management and lifetime extension.

An important connecting link between the recording of measurements and the stress and fatigue analysis is the load data evaluation (see Figure 1) and the specification of thermal loads in transient catalogues. Expert knowledge of the processes and the operation of the systems is essential. The first step to specify thermal loads is the identification of the operational processes leading to relevant transients of temperature and/or pressure. For these events an appropriate number of model transients is selected. Usually, it is necessary to split up these model transients into subclasses which are different e.g. in the temperature difference of the transient. As it is shown in Figure 1 the specified transients are input data for the detailed fatigue check.

Indeed, three graded methods were developed fulfilling the different requests in terms of fatigue. The choice of one method depends on the expected degree of fatigue relevance and the expected grade of details in fatigue calculation.

\section{Step 1: Simplified fatigue estimation}

Simple estimations of fatigue relevance of real loads for components are based on thermal mechanical considerations using the equation of completely restrained thermal expansion. A basic decision about fatigue relevance (yes/no) for the monitored position is made. In case of fatigue relevance a further evaluation is done according to step 2.

\section{Step 2: Fast fatigue evaluation}

A code-conforming usage factor $U$ is calculated in a highly automated way based on the simplified elasto-plastic fatigue analysis. If $U \leq U_{\text {admissible }}$ the fatigue check will be successfully finished. If $U>U_{\text {admissible }}$ further analyses will be based on step 3 .

\section{Step 3: Detailed fatigue calculation}

Fatigue analysis is based on a detailed catalogue of transients. This catalogue of transients results from the evaluation of the real loads for the monitored component. The detailed fatigue check is based on finite element analyses mostly including elasto-plastic material behavior.

Both step 2 and step 3 allow for the consideration of EAF in the analysis process.

\section{Simplified fatigue estimation}

The results of the temperature measurement are to be processed quickly in order to get a first estimation of the fatigue state. One important task before the simplified and automated 
evaluation is the verification of the acquired data. Detection and adjustment of implausible data are parts of this process. In this context, data plausibilization is based on the limits of the measurement range (e.g. $0^{\circ} \mathrm{C}-400^{\circ} \mathrm{C}$ ) as well as the predefined limiting gradients. Irregularities such as those resulting from the switching of the main coolant pump by electromagnetic pulses are recognized and corrected this way. The original set of data is not modified. All adaptations are reproducibly recorded. These plausibility and quality checks of the measured data have to be done by experienced specialists. In other words, the specialists must be capable of checking the operational events with respect of their plausibility. The result is a preprocessed database for data evaluation and fatigue assessment.

In the very first step of the SFE, the changes of temperatures are subject to a rain-flow cycle counting algorithm (see e.g. [9] and [10]). In this process the temperature ranges at the locations of measurement are identified, counted and classified. The according temperature differences between a subsequent minimum and maximum are inserted into a rain-flow matrix. The temperature difference, the starting value and the temperature change as well as the stratification differences are the parameters of this matrix. An exemplary matrix is shown in Figure 5.

These thermal load cycles are input data for a stress and fatigue assessment of the monitored components based on conservative analytical computation formulae.

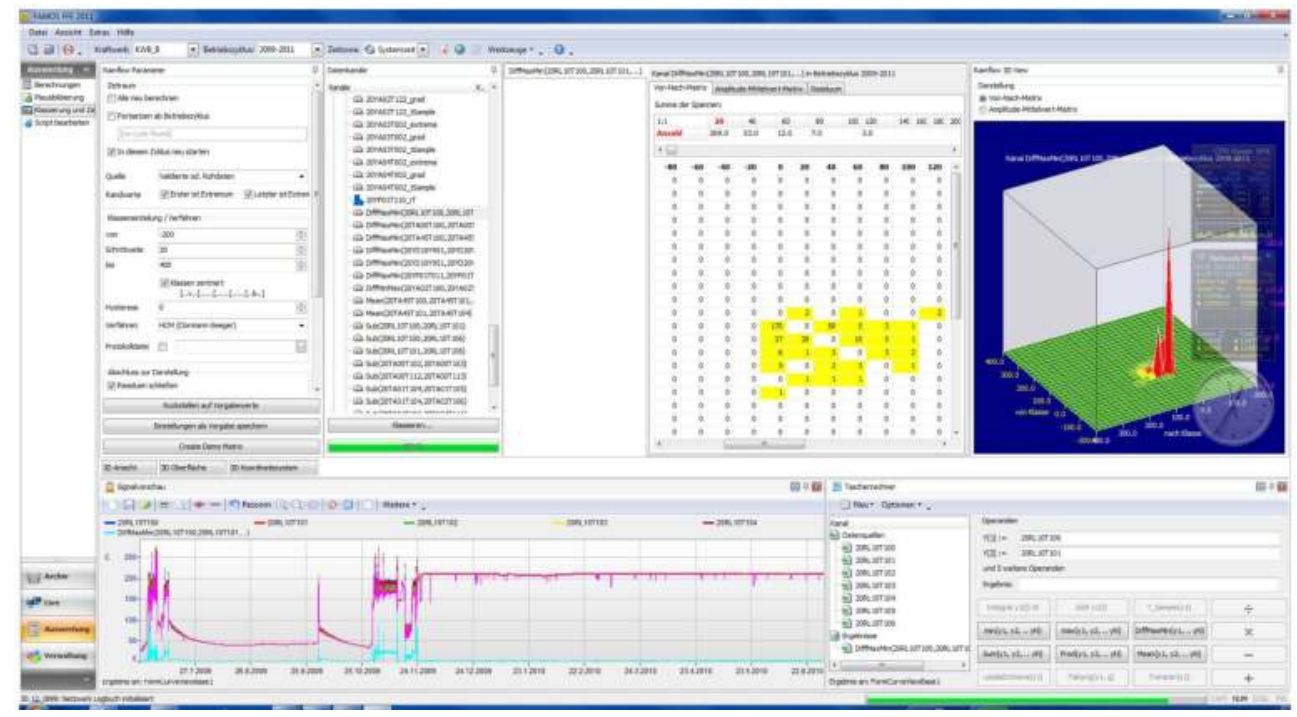

Fig. 5. Exemplary rain-flow matrix for SFE application

The temperature differences are processed to stresses by applying the equation of the completely restrained thermal extension $\sigma=\mathrm{E} \cdot \alpha \cdot \Delta \mathrm{T}(\sigma \ldots$ Stress, E ... Young's modulus, $\alpha \ldots$ coefficient of thermal extension, $\Delta \mathrm{T} \ldots$ temperature difference). The internal pressure induced stresses are added. The stresses calculated in this way are multiplied by stress concentration factors as a function of the component geometry. The well-known stress concentration factors for pipe bends, t-joints or weld seams (see e.g. chapters on piping design in the ASME code [1] 
or the KTA rules [4]) are applied. Based on these stresses and their frequency of occurrence the partial usage factors are calculated and summed up to the total usage factor. The basic function of this method is a check of fundamental fatigue relevance of the component subjected to the recorded loading. It constitutes a simple qualitative assessment method. In case of calculated CUFs $<5$ per cent there is no fatigue relevance of the component. Additionally, SFE allows for a simple qualitative comparison of annual partial usage factors. By means of extrapolation the future fatigue potential can be predicted.

SFE has been successfully applied in many German NPPs for about 20 years. This rough real time fatigue estimation is done after every operational cycle and allows for a direct comparison of thermal loads and an evaluation of the current fatigue usage factor. The result of this SFE provides a qualitative tendency. Although the correlation of the real temperature ranges is fairly simple, it is suitable for a comparison of different real sequences of loads and allows for a qualitative evaluation of the mode of operation and the detection of fatigue critical locations. Furthermore, the investigation of the results allows for the detection of anomalies.

\section{Fast fatigue evaluation}

\subsection{General remarks and context}

With the help of the fast running SFE method, an overview of the fatigue level for every monitored component is given. For highly loaded components a more detailed method, the FFE, can be used to calculate the usage factors in a more realistic way as indicated in [11]. This method uses FAMOS measured data from the outside surface of a pipe and can evaluate a fatigue level of the component for different thermal loads (plug flow, stratification).

The measuring location of FAMOS is chosen close to a fatigue relevant component and the measurement sections installed at the outer surface of the pipe. Nevertheless, the points of interest are at the inner surface of the component. Therefore, the calculated temperature at the inner surface of the pipe will be transferred to the inner surface of the component. The thermal load cycles are well known after that step and the stress time history is calculated with the Green's function approach. This approach deals with two unit (elementary) transients of $+/-100 \mathrm{~K}$, which are used to scan the original temperature time history at each time step. By means of elementary transients, stresses are calculated at all fatigue relevant locations, which are monitored with FAMOS. Pressure cycles as well as section moments will also be evaluated based on the Green's function approach.

After the calculation of the stress tensor, the mechanical load cycles can be classified by application of the rain-flow cycle-counting algorithm. Then, comparisons with the fatigue curve result in fatigue levels and are performed for all relevant locations.

Moreover, an enveloping fatigue level can still be calculated. In other words, for highly loaded components, the application of the FFE method can provide a more realistic stress calculation and enveloping fatigue level calculation. Depending on the real number of load cycles, the new and more stringent code requirements can also be complied with.

In the end, if the calculated fatigue usage factor is lower than the allowable limit, the fatigue check will be successfully finished. If not, further analyses will be performed, according to the detailed fatigue calculation (DFC). 


\subsection{Detailed description}

The fast running SFE method draws up an overview of the temperature changes and a qualitative stress estimation for every monitored component. The fatigue handbook and the knowledge of these parameters determine the pertinence of a fatigue analysis for the component. In that way a more detailed and automatic method, FFE, can be used to calculate the CUFs.

The determination of the time-history of loads and the resulting local stresses are the basis of the method. On a measuring section, close to the fatigue relevant location, FAMOS measures the temperature at the outside surface of the pipe. First of all the interpretation of this temperature has to be explained.

In a homogeneous isotropic solid, where the temperature is a function of time and space $T=f(x, y, z, t)$, the equation of heat conduction is as follows:

$$
\frac{\partial^{2} T}{\partial x^{2}}+\frac{\partial^{2} T}{\partial y^{2}}+\frac{\partial^{2} T}{\partial z^{2}}-\frac{\rho c}{\lambda} \frac{\partial T}{\partial t}=0
$$

$\lambda \ldots$ thermal conductivity of the solid $[\mathrm{W} /(\mathrm{m} \cdot \mathrm{K})]$

$\rho$... density of the solid $\left[\mathrm{kg} / \mathrm{m}^{3}\right]$

c ... specific heat of the solid $[\mathrm{J} /(\mathrm{kg} \cdot \mathrm{K})]$

This equation can be written in a cylindrical coordinate system:

$$
\frac{\partial^{2} T}{\partial r^{2}}+\frac{1}{r} \frac{\partial T}{\partial r}+\frac{1}{r^{2}} \frac{\partial^{2} T}{\partial \theta^{2}}+\frac{\partial^{2} T}{\partial z^{2}}-\frac{\rho c}{\lambda} \frac{\partial T}{\partial t}=0
$$

The stratification effects will not be considered here and the application of the method will be restricted to plug flow events. In this case, the temperature evolution is independent of the circumferential direction $T=f(r, z, t)$. Moreover the measuring section on the pipe is located relatively far away from geometrical discontinuities and $T(z-\delta z)=T(z+\delta z)$ holds true. Following this presumption, the temperature in the assessed section can be written as: $T=f(r, t)$. This involves:

$$
\frac{\partial^{2} T}{\partial r^{2}}+\frac{1}{r} \frac{\partial T}{\partial r}=\frac{\rho c}{\lambda} \frac{\partial T}{\partial t}
$$

This equation handles the thermal evolution inside the thickness of the pipe. The solution of the equation depends on the applied boundary conditions. As the varying load is the medium temperature flowing throughout the component, the heat transfer between the fluid and the inner surface is governed by a Newton's law of cooling:

$$
\left.\lambda \frac{\partial T}{\partial r}\right|_{r=r i}=h\left(T-T_{\infty}\right)_{r=r i}
$$

$\mathrm{h}$... heat transfer coefficient $\left[\mathrm{W} /\left(\mathrm{m}^{2} \cdot \mathrm{K}\right)\right]$

For further explanations of the mathematical background of the method see e.g. [12]. 
All the difficulty to apply this equation during unsteady fluid temperature states is due to the determination of the heat transfer coefficient $h$. Indeed, this parameter depends on the velocity, the thermo-hydraulics conditions and the geometry of the surface. The time dependent knowledge of all these parameters with sufficient accuracy is hardly compatible with a fast determination of the real loads. To solve this problem, the inverse philosophy was developed to calculate the stresses in the structure. Indeed, to perform a structural analysis, the knowledge of the temperature distribution throughout the wall is sufficient. The FFE method is based on the time history determination of the inner wall temperature by solving the inverse problem of conduction of heat. The according flowchart is shown in Figure 6.

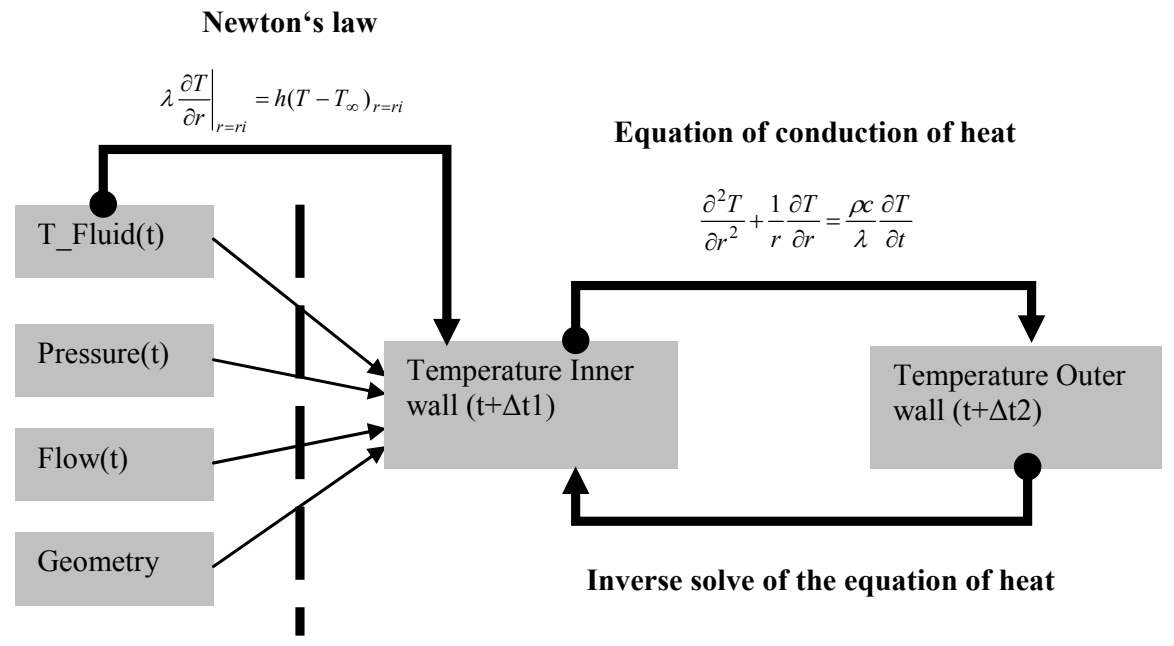

Fig. 6. Different way to get inner wall temperature

Solving the inverse conduction equation of heat is done by application of potential functions (unit transients). A unit transient is applied at the inner surface of the pipe (boundary condition), the equation of conduction of heat is solved, the resulting time-history of temperature at the outer wall is observed. The resolution of the equation of heat can be done by means of an analytical method or with the help of a finite element program (ANSYS ${ }^{\circledR}$ ). In that case a two-dimensional model of the section of the pipe is generated. The benefit of this last choice is the opportunity to integrate the thermal influences of the thermocouple installation at the outer surface of the pipe in the solution (see Figure 7).

The determined temperature response calculated in the thermocouple (outer wall) will be considered as a reference. Its evolution is characteristic by the applied unit transient at the inside surface of the pipe (characterized by a temperature rate of changes and a thermal amplitude $\Delta \mathrm{T}_{\text {ref }}$ ). Thus the FAMOS measured outside temperature will be scanned step by step (typically every second). The temperature difference at the outer wall between two time steps is compared with the simulated outer wall temperature (reference). The factor resulting from this comparison is through linearity properties also available at the inner side of the structure. Thus, step by step the inside temperature of the pipe can be restituted. A computation algorithm of this process was developed. The acquired measured data of FAMOS are read into the FFE program. A preparatory work consists of calculating, for the 
different observed piping sections, the thermal references. These last ones depend on the material, pipe thickness and measurement thermocouple. After this pre-processing work, the computation of the transient inner wall temperatures is completely automated.

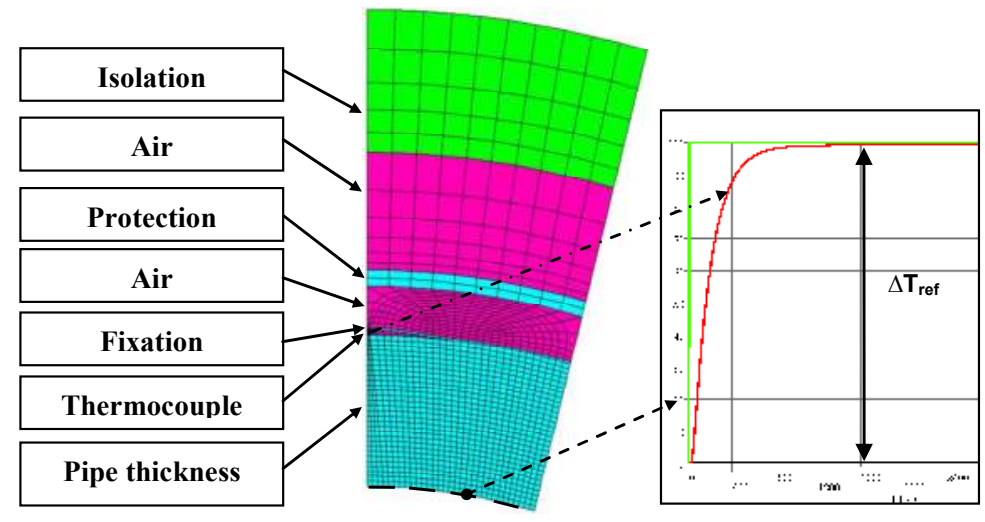

Unit Transient applies at the inside surface of the pipe

Fig. 7. FE calculation of the temperature response at the outside of the pipe

The determined inner wall temperature will be used to calculate the thermal stress at the fatigue relevant locations. An appropriate temperature transfer function can readily be used for correction of the axial dependency of the temperature if the FAMOS section is far away from the stress calculation locations $T(z-\delta z) \neq T(z+\delta z)$. The procedure is shown schematically in Figure 8.

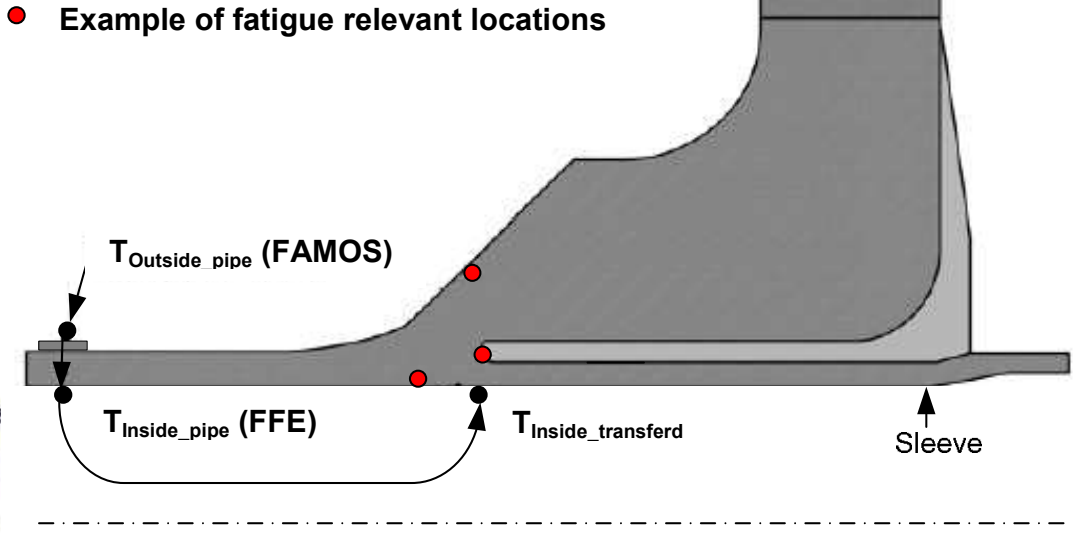

Fig. 8. Inner wall calculation and transfer of thermal loads to the fatigue relevant locations 
The thermal stress determination is done according to a similar process as previously explained. A two- or three- dimensional finite element model of the monitored component is generated (nozzle, heat exchanger,...). A unit (elementary) transient is used as a reference load of a thermal calculation. Thus, the thermal field in the structure is calculated. Subsequently, the thermal stresses are calculated by a linearly elastic structural analysis.

The resulting thermal stresses are determined for typical fatigue relevant locations. The calculated stress components are the response to a reference load characterized by a temperature rate of change and a thermal amplitude $\Delta \mathrm{T}_{\text {ref. }}$. The exemplary procedure is shown in Figure 9.

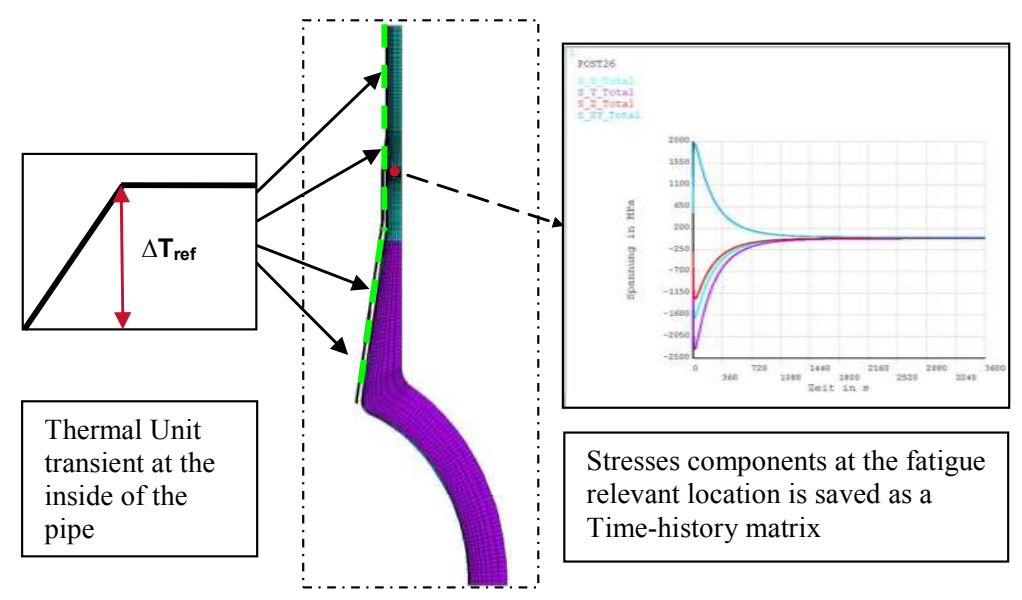

FE model of the analyzed component

Fig. 9. FE calculation of the stress responses at a fatigue relevant location

The inside temperature calculated in the previous step by means of FFE, is scanned step by step. Between two time steps, the temperature difference is interpreted as a unit transient the amplitude of which is compared to the reference unit transient of amplitude $\Delta \mathrm{T}_{\text {ref }}$. Because of linearity in the thermal stress calculation, the comparison between the measured amplitude and the reference gives a coefficient to be applied to the reference stress matrix in order to obtain the stress contribution resulting from the thermal load at the calculated time. The time-dependent stress components are then obtained by the summation of all these single contributions. The process is also completely automated within the FFE program. The stress matrix references have to be calculated previously in an FE program. The results are then added to the database of FFE: it is the pre-processing work. Subsequently, the calculation at the selected locations can be processed. Within a few minutes, thermal loads and stress components of the entire operating cycles are calculated (see e.g. Figure 10).

If information on the time dependent pressure or piping section forces and moments are available based on operational instrumentation, the resulting mechanical stress components can be calculated equally by means of FFE (scaling of unit loads). Thermal and mechanical 
stress components are added and the equivalent stress is calculated. The use of a rain-flow algorithm will classify the stress ranges, a standard conform comparison with the fatigue curves will give the fatigue level of the selected locations.

Finally, if the calculated fatigue usage factor is lower than the allowable limit, the fatigue check will be successfully finished. If not, further analyses according to the detailed code based fatigue check will be performed.

In order to optimize the costs and user flexibility, the FFE program was based on a modular architecture. Thus, only information required by the customer/user is calculated. This architecture also permits an easy upgrade of the program to implement new modules e.g. as a consequence of changes of nuclear standards (new fatigue curves, environmental factor integration,...) or further calculation methods (automated stratification consideration).

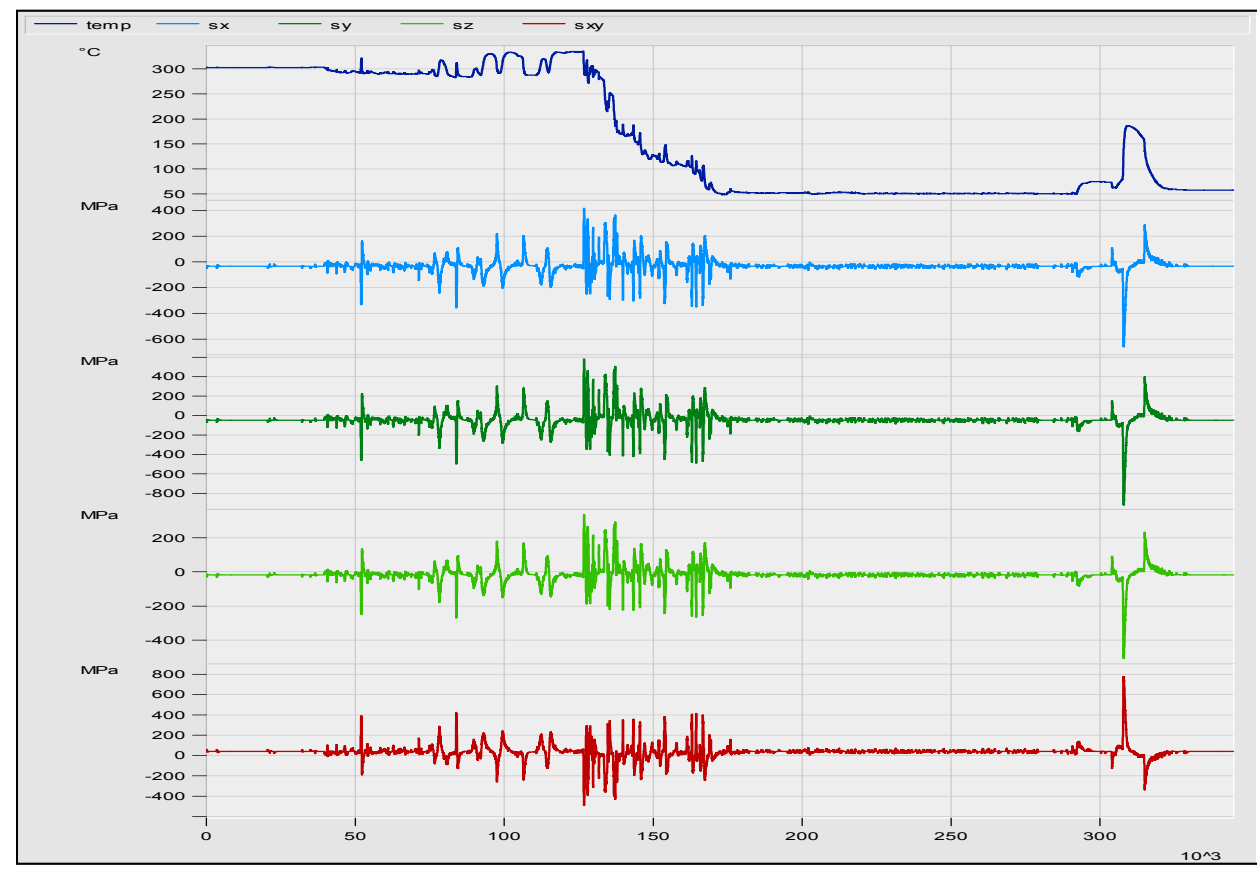

Fig. 10. FFE temperature and thermal stresses calculation for shut down event

\section{Detailed fatigue calculation}

\subsection{General remarks and context}

The detailed fatigue calculation (DFC) is usually carried out after a certain time period of plant operation, every ten years for instance. These analyses are often performed in the framework of the periodic safety inspection (PSI). Loading data of the operational period as well as anticipated loads of future operation are used as essential input parameters. Hence, usage factors are calculated for the current state of the plant and some prognoses are taken into account to get results until the end of life. 
The simplified elasto-plastic fatigue analysis based on elastic FE analyses and plasticity correction (fatigue penalty or strain concentration factors $K_{e}$ ) e.g. according to paragraph 7.8.4 of [4] or equally NB 3228.5 of [1] is known to yield often overly conservative results.

In the practical application this may yield high calculated usage factors. As a consequence, the less conservative elasto-plastic fatigue analysis method based on non-linear FE analyses will often be used for fatigue design. This is associated with an increased calculation effort. Computing times for complex geometries and numerous transients may be significant. Under these circumstances the specified transients have to be rearranged in a small set of covering transients, approximately ten, for calculation purposes.

The possible modification of design codes in respect of more severe fatigue curves and particularly the consideration of EAF will significantly influence the code based fatigue design. Of course, these developments are attentively followed and actively accompanied; see "supporting functions" in Figure 1.

The usual workflow of the fatigue analysis of NPP components is shown in Figure 11. The structural analysis might be simplified elasto-plastic or fully elasto-plastic. The transient temperature fields are analyzed for all relevant $N$ model transients according to Figure 11. These transient temperature fields are themselves the input data for the subsequent transient (linear or non-linear) structural mechanical analyses yielding the local stresses and strains required for code-conforming fatigue assessment. Cycle counting is done in accordance with the requirements of the ASME code as implemented in the ANSYS ${ }^{\circledR}$ Classic Post 1 Fatigue module. It is explained in more detail in the following section.

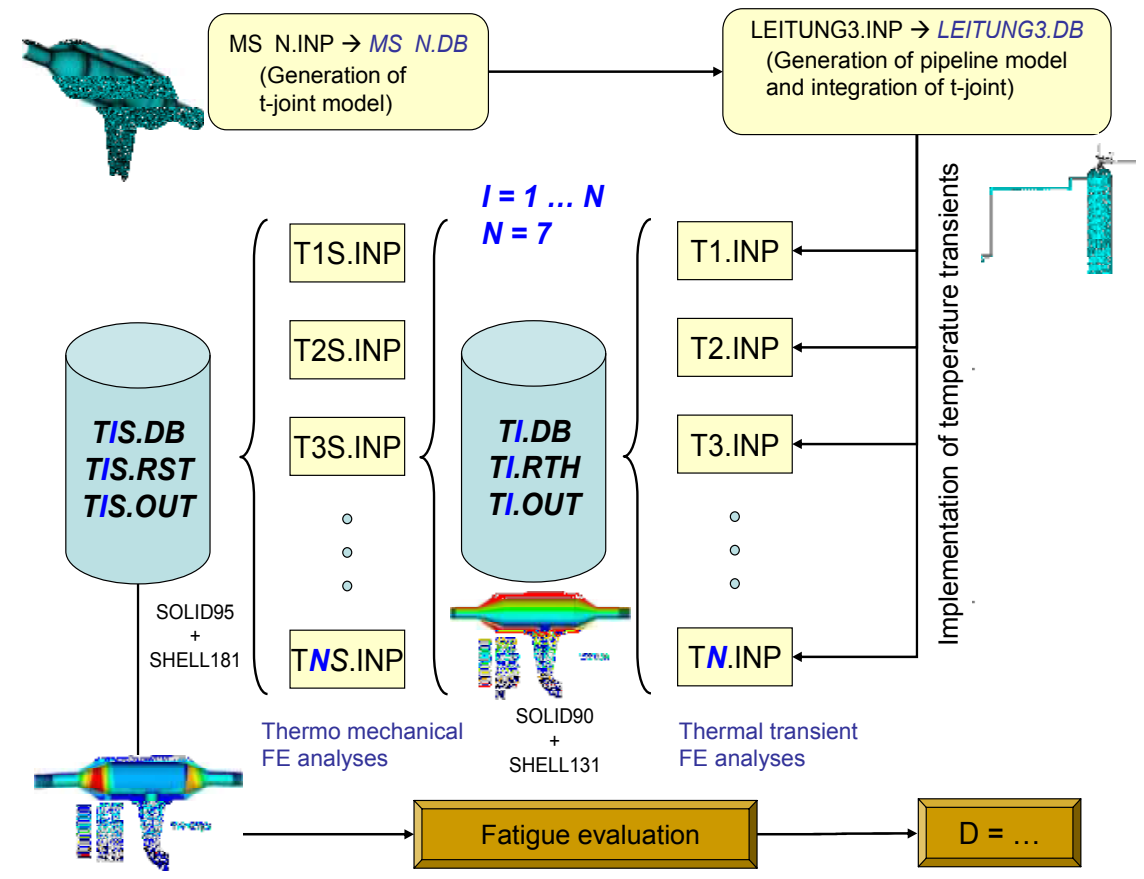

Fig. 11. Workflow of detailed fatigue analyses 


\subsection{Cycle counting}

Cycle counting is the prerequisite for any fatigue or service durability assessment method dealing with arbitrary operational load sequences. Consequently, an appropriate cycle counting algorithm is required.

Cycle counting methods in general are characterized by the following features [10]:

- decomposition of a given course of load (stress) - time history into a sequence of reversal points

- definition of a relevant elementary event (e.g. hysteresis)

- formulation of an algorithm for the detection and processing of elementary events.

The superposition of transients according to the design code (ASME Code, NB 3222.4, see Figure 12) is based on the peaks and valleys method. The largest stress ranges are usually determined from "outer combinations" (e.g. load steps across different transients respectively events). The associated frequency of occurrence results from the actual number of cycles of the participating two events with the smaller number of cycles. This event provides the associated contribution to the partial usage factor $U_{i}$. The summing up of all partial usage factors according to Miner's rule delivers the accumulated damage (usage factor $U$ ) or cumulated usage factor CUF.

\section{Extreme value method}

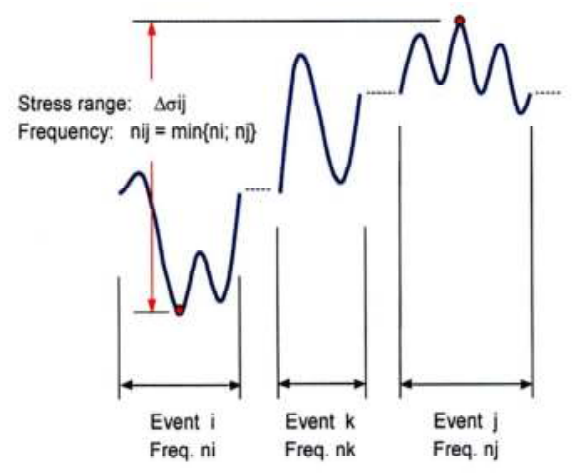

2007 SECTION III, DIVISION 1 - NB

NB-3222.4 Analysis for Cyclic Operation

(5) Cumulative Damage.

- Usual counting method according to ASME-Code

- Search for the largest stress range across events („external combinations“)

- e.g. implemented in ANSYS ${ }^{{ }_{-}}$ postprocessing

Fig. 12. Cycle-counting method according to [1]

Additionally, a counting of sub cycles within the events should be carried out according to the rain-flow cycle-counting method [e.g. 10] although it is not explicitly addressed by the design code [1]. This is standard practice in the framework of the AFC. The Hysteresis Counting Method (HCM) according to Clormann and Seeger [10] is applied for this purpose. Additionally, the introduction of so called basic events allows a more realistic consideration of the load time sequence [13]. 


\subsection{Application example}

As an application example, the spray line of a PWR system is subject of a detailed codebased fatigue analysis. The load input covers the temperature transients measured during operation. Figure 13 gives an example of a specified temperature transient. This specification of the plant-specific thermo-hydraulic loads in official reports and transient handbooks is realistic, but still conservative. It is obvious that the load specification takes a decisive influence on the fatigue usage calculation and is a source of conservatism.

In the subsequent calculation process all relevant loads and relevant components have to be considered. Furthermore the interaction between the components and the adjacent piping system (supplementary loads resulting from the deformation of the piping sections) cannot be neglected. Based on this requirement, a decision was taken to model the complete spray line system by means of shell type elements. This model containing the spray line, the auxiliary spray line, and the pressurizer is shown in Figure 14. It allows for the identification of realistic transient piping loads on the fatigue relevant components which are modeled in detail based on brick type elements.

The spray line nozzle, the spool, and the t-section (see Figure 15) were identified as fatiguerelevant components within the spray line system. In a next step, detailed brick type FE models of these three components were generated and integrated into the overall shell type model of the spray line. It is pointed out that the detailed models were considered subsequently and not simultaneously due to model and file sizes as well as analysis time. Some model statistics are given in Figure 16 for the example of the t-section.

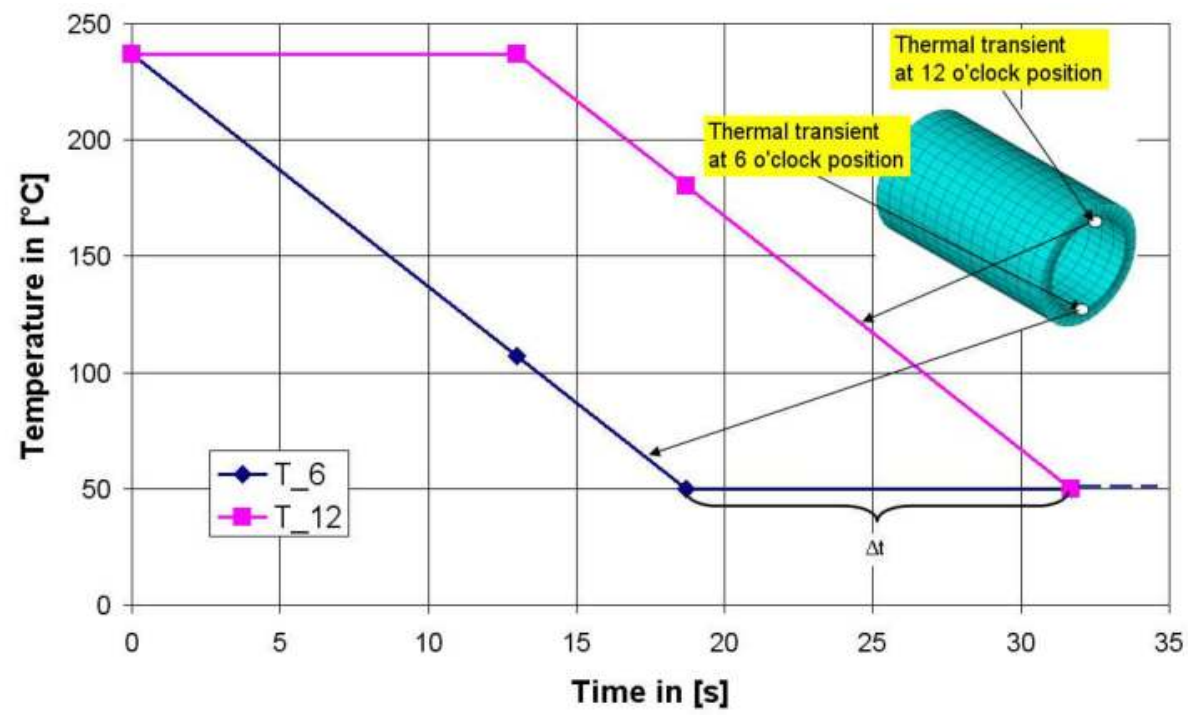

Fig. 13. Example of a specified temperature transient

The connection between the shell type and the brick type part of the complete model is achieved by constraint equations (CE) in the case of the transient temperature field analyses and by means of multiple point constraints (MPC) in the case of the structural mechanical 
analyses. Nearly one million nodes yield considerable computing times in the transient nonlinear analyses. The complete workflow of the fatigue analysis is shown in Figure 11. A simplified elasto-plastic fatigue analysis was not applicable in this application example. All transient analyses were based on a nonlinear material law with kinematic hardening.

The transient temperature fields were analyzed for all relevant $\mathrm{N}$ model transients according to Figure 11. These transient temperature fields were the input data for the subsequent transient nonlinear structural mechanical analyses yielding the local strains required for code-conforming fatigue assessment. Note that the code-conforming damage accumulation algorithm is not trivial in the case of elasto-plastic analyses. More details on the implementation can be found in [14]. Cycle counting was done in accordance with the requirements of the ASME code as implemented in the ANSYS ${ }^{\circledR}$ Classic Post 1 Fatigue module.

An example of the temperature distribution in the t-joint is shown in Figure 17. It represents one point of time of one model transient. Note that the temperature distribution remains continuous at the border between the solid type and the shell type part of the model. The resulting von-Mises stress distribution for the same point of time is shown qualitatively in Figure 18. Again, the stress distribution remains continuous at the border between the solid type and the shell type part of the model. The MPC approach works very well. It is clearly shown that the thick walled transition regions and thermal sleeve connections are particularly prone to fatigue damage.

Consequently, the fatigue usage analysis revealed the thick walled transition region to be the most relevant location for the fatigue check. Only the elasto-plastic fatigue analysis assured fatigue usage below the admissible value of 1.0.

For more details on the code-conforming fatigue check and associated further developed methods see e.g [15].

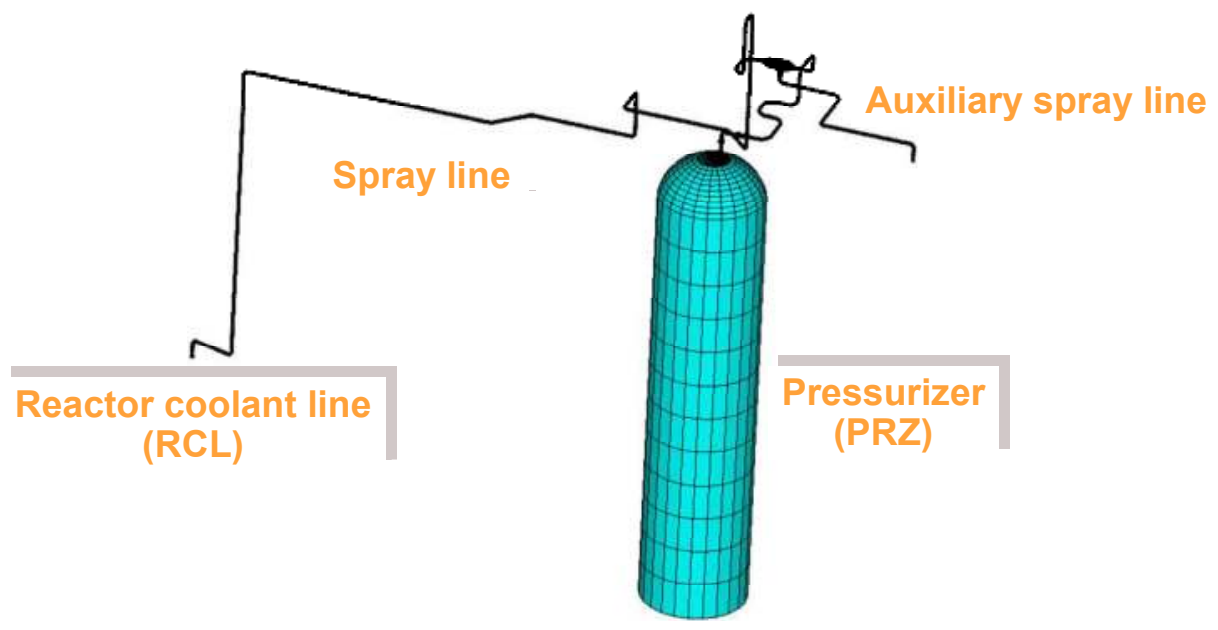

Fig. 14. FE model of spray line and pressurizer (shell type elements) 


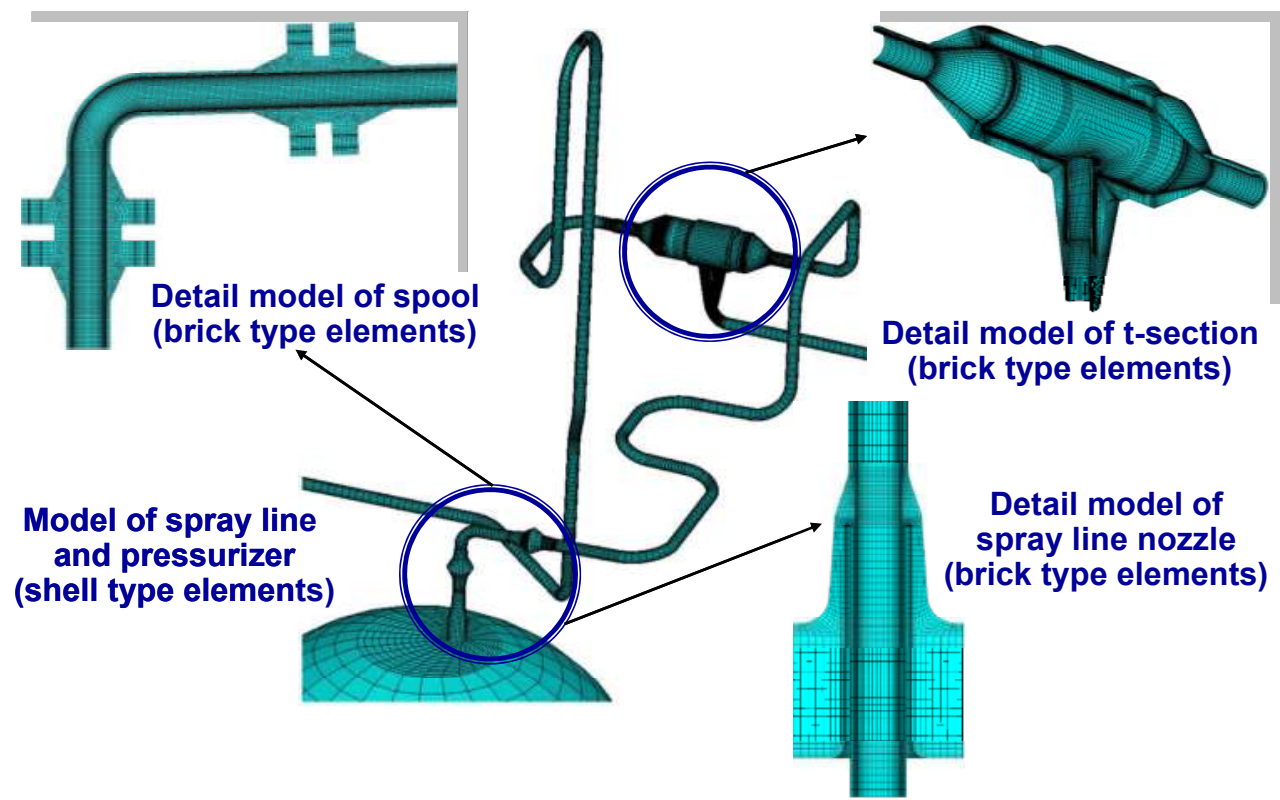

Fig. 15. Detail models of spray line nozzle, spool and t-section

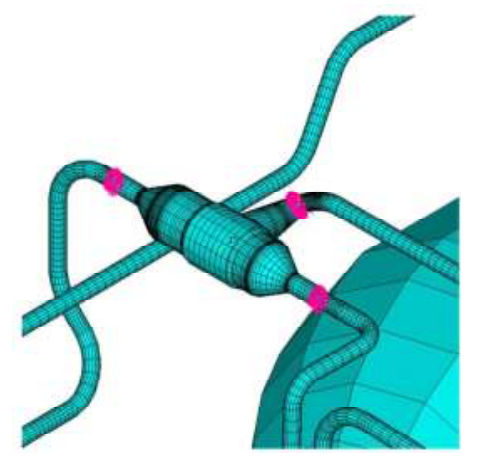

Transient temperature field analyses:

- SHELL131 + SOLID90

- Constraint equations (CE)

Structural mechanical analyses:

- SHELL181 + SOLID95

- „Multiple Point Constraints“ (MPC)

Model statistics:

- 912281 nodes, 243120 elements

- 9 supports

- Pipeline (SHELL):

35700 nodes, 35568 elements

- $T$-joint (SOLID):

877331 nodes, 207552 elements

Fig. 16. Model statistics for the $\mathrm{t}$-section 


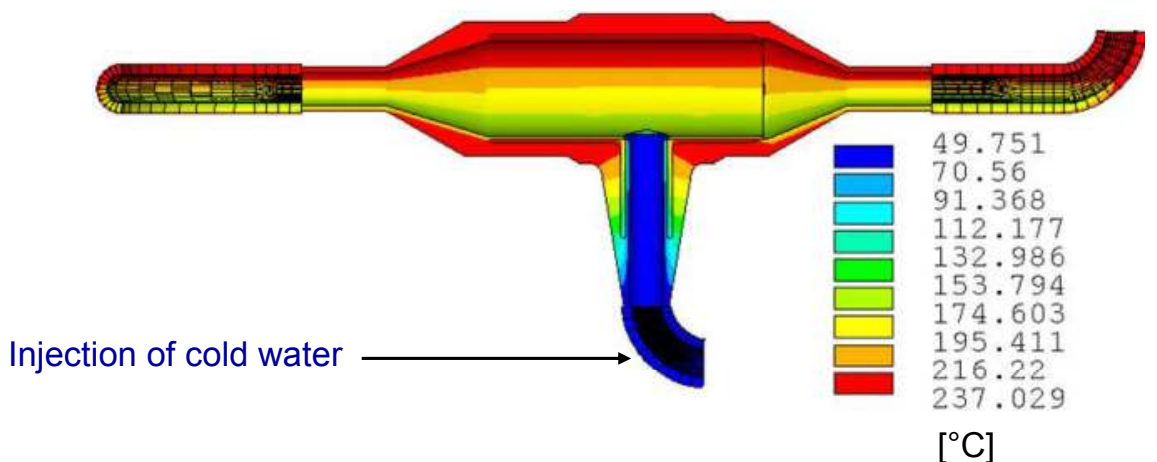

Fig. 17. Exemplary temperature distribution in the t-joint

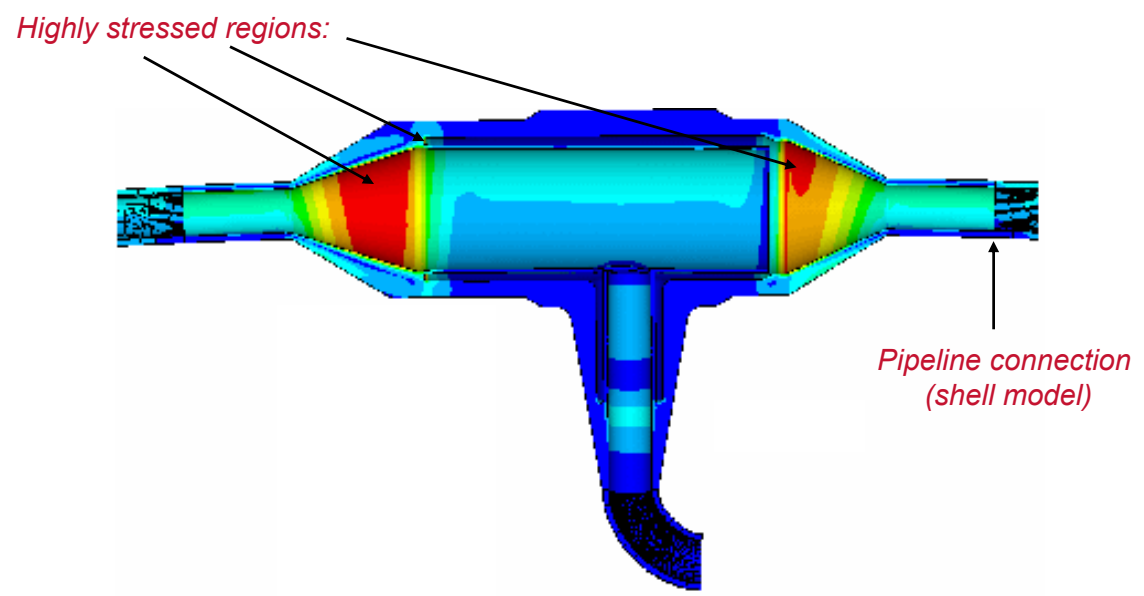

Fig. 18. Exemplary von-Mises stress distribution in t-section due to thermal loading

\section{Conclusions}

The AREVA integrated and sustainable concept of fatigue design expresses the importance of design against fatigue in NPPs. Actually, new plants with scheduled operating periods of 60 years, lifetime extension, the modification of the code based approaches and the improvement of operational availability are driving forces in this process. Therefore, applying the AFC is an expression of responsibility sense, as well as an economic requirement. Moreover, the fatigue concept is widely supported by measured data. Indeed, the results of the fatigue monitoring can be the basis for decisions of optimized operating modes and thus influence the fatigue usage factors.

The main modules are FAMOS, the first design analysis before operation, and the three stages of fatigue data evaluation. As all modules are closely connected, it is reasonable to apply the approach as a whole, with an additional cost reduction effect, compared to separate solutions. An integrated software ensures the effective data processing from 
measurement to fatigue data calculation and offers the user an easy to use interface to NPP's loading data. Thus, the integrated fatigue approach makes a significant contribution to the safety margins monitoring, the operational availability and the protection of investment.

\section{Acknowledgment}

The authors wish to express special thanks to all contributors to the AFC within AREVA.

\section{References}

[1] ASME Boiler and Pressure Vessel Code, 2007 Addendum 2009b Section III, Division 1 Subsection NB: Class 1 Components. "Rules for Construction of NPP Components"

[2] Chopra, O. K.; Shack, W. J.: "Effects of LWR Coolant Environments on the Fatigue Life of Reactor Material" NUREG/CR-6909 ANL-06/08, Argonne National Laboratory for U.S. Nuclear Regulatory Commission

[3] KTA rules (Safety Standards of the Nuclear Safety Standards Commission). KTA 3201.4 (06/96): Components of the Reactor Coolant Pressure Boundary of Light Water Reactors. Part 4: In-service Inspections and Operational Monitoring. (Komponenten des Primärkreises von Leichtwasserreaktoren; Teil 4: Wiederkehrende Prüfungen und Betriebsüberwachung)

[4] KTA rules (Safety Standards of the Nuclear Safety Standards Commission). KTA 3201.2 (06/96), 1996: Components of the Reactor Coolant Pressure Boundary of Light Water Reactors. Part 2: Design and Analysis (Komponenten des Primärkreises von Leichtwasserreaktoren; Teil 2: Auslegung, Konstruktion und Berechnung)

[5] RCC-M, Edition 2007: “Design and Construction Rules for Mechanical Components of PWR Nuclear Islands"Section I, Subsection B: Class 1 components.

[6] Kleinöder, W.; Poeckl, C.: "Developing and implementation of a fatigue monitoring system for the new European pressurized water reactor EPR"Proceedings of the International Conference "Nuclear Energy for New Europe 2007", September 10-13, 2007, Portoroz, Slovenia

[7] Miksch, M.; Schön, G.; Thomas, B.: "FAMOS - a tool for transient recording and fatigue monitoring"PVP-Vol. 138/NDE-Vol. 4 "Life extension and assessment: nuclear and fossil power plant components", presented at the 1988 ASME Pressure Vessels and Piping Conference, Pittsburgh, Pennsylvania, June 19-23, 1988

[8] Abib, E.; Bergholz, S.; Pöckl, C.; Rudolph, J.; Bergholz, S.; Wirtz, N.: “AREVA Fatigue Concept (AFC) - an integrated and multi-disciplinary approach to the fatigue assessment of NPP components." Proceedings of ICAPP 2011, Nice, France, May 25, 2011, Paper 11027

[9] Matsuishi, M.; Endo, T.: "Fatigue of metals subjected to varying stresses"Proceedings of the Kyushu branch of the Japanese Society of Mechanical Engineers, pp 37/40; March 1968

[10] Clormann, U.H.; Seeger, T.: "Rainflow - HCM, ein Zählverfahren für Betriebsfestigkeitsnachweise auf werkstoffmechanischer Grundlage". Stahlbau 55 (1986), Nr. 3, S. $65 / 71$

[11] Heinz, B., 2010: “AREVA Fatigue Concept - a new method for fast fatigue evaluation"PVP2010-25935; Proceedings of the ASME 2010 Pressure Vessels \& Piping Division Conference; July 18-22, 2010, Bellevue, Washington, USA 
[12] Carslaw H.S-; Jaeger, J.C.: „Conduction of heat in solids“Oxford University Press, 2nd edition. 1959

[13] Lang, H.: "Fatigue - Determination of a more realistic usage factor" Nuclear Engineering and Design 206 (2001), S. 221/234

[14] Rudolph, J.; Götz, A.; Hilpert, R.: “Code-conforming determination of cumulative usage factors (CUF) for general elasto-plastic finite element analyses"Proceedings of ANSYS Conference \& 29th CADFEM Users' Meeting 2011, October 19-21, 2011 Stuttgart, Germany

[15] Rudolph, J.; Bergholz, S.; Willuweit, A.; Vormwald, M.; Bauerbach, K.: “Methods of detailed thermal fatigue evaluation of NPP components". Proceedings of SoSDiD 2011, May 26th-27th, 2011 Darmstadt, Germany 


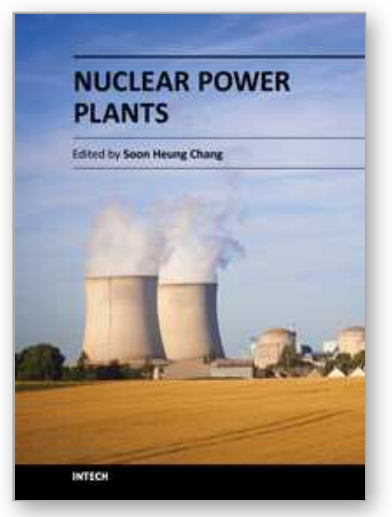

\author{
Nuclear Power Plants \\ Edited by Dr. Soon Heung Chang
}

ISBN 978-953-51-0408-7

Hard cover, 340 pages

Publisher InTech

Published online 21, March, 2012

Published in print edition March, 2012

This book covers various topics, from thermal-hydraulic analysis to the safety analysis of nuclear power plant. It does not focus only on current power plant issues. Instead, it aims to address the challenging ideas that can be implemented in and used for the development of future nuclear power plants. This book will take the readers into the world of innovative research and development of future plants. Find your interests inside this book!

\title{
How to reference
}

In order to correctly reference this scholarly work, feel free to copy and paste the following:

Jürgen Rudolph, Steffen Bergholz, Benedikt Heinz and Benoit Jouan (2012). AREVA Fatigue Concept - A Three Stage Approach to the Fatigue Assessment of Power Plant Components, Nuclear Power Plants, Dr. Soon Heung Chang (Ed.), ISBN: 978-953-51-0408-7, InTech, Available from:

http://www.intechopen.com/books/nuclear-power-plants/areva-fatigue-concept-afc-a-three-stage-approach-tothe-fatigue-assessment-of-power-plant-components

\section{INTECH}

open science | open minds

\section{InTech Europe}

University Campus STeP Ri

Slavka Krautzeka 83/A

51000 Rijeka, Croatia

Phone: +385 (51) 770447

Fax: +385 (51) 686166

www.intechopen.com

\section{InTech China}

Unit 405, Office Block, Hotel Equatorial Shanghai

No.65, Yan An Road (West), Shanghai, 200040, China

中国上海市延安西路65号上海国际贵都大饭店办公楼 405 单元

Phone: +86-21-62489820

Fax: +86-21-62489821 
(C) 2012 The Author(s). Licensee IntechOpen. This is an open access article distributed under the terms of the Creative Commons Attribution 3.0 License, which permits unrestricted use, distribution, and reproduction in any medium, provided the original work is properly cited. 